\title{
Note on Language
}

The values of letters I use to write Korowai speech probably do not need special clarification, with the following exceptions. I use $[\mathrm{x}]$ to represent a velar fricative (like the sound written as $[\mathrm{kh}]$ in Indonesian). I use [ə] to represent a mid-central unrounded vowel (like the first sound in English about), which occurs only in unstressed syllables. The consonant written as [f] is bilabial rather than labiodental. I use [j] to represent a voiced palatal stop.

Korowai speech appears in italics. In the few places where I cite Indonesian words, these are underlined.

In places where it might be useful for readers to see morpheme boundaries within single Korowai words (such as between two parts of a compound), I separate the different meaningful parts of the words by hyphens. In other places, where the hyphens are more likely to be distracting than informative, I do not break single words up in this way. When I cite an uninflected verb root, I put a hyphen at the end to indicate that the form is always accompanied in speech by suffixes. I also put hyphens at the beginning or end of other kinds of bound morphemes cited in isolation, to indicate that they do not occur in speech as self-standing words.

In photograph captions and in my acknowledgments, I identify specific Korowai persons by binomials consisting of a personal name followed by a clan name. Korowai do not combine personal names and clan names in this way, except as a new, occasional practice associated with writing, government institutions, and commerce. 
This Page Left Intentionally Blank 